\title{
PROFISSIONAL DE APOIO COMO MEDIADOR DA TECNOLOGIA ASSISTIVA NO AMBIENTE ESCOLAR ${ }^{1}$
}

\author{
PROFESIONAL DE APOYO COMO MEDIADOR DE TECNOLOGÍA DE APOYO EN \\ LA ESCUELA
}

\author{
PARAPROFESSIONAL AS MEDIATOR OF ASSISTIVE TECHNOLOGY IN THE \\ SCHOOL ENVIRONMENT
}

\author{
Fernanda Matrigani Mercado Gutierres de QUEIROZ ${ }^{2}$ \\ Márcia Helena da Silva MELO ${ }^{3}$
}

RESUMO: Todos os estudantes têm potencialidades a desenvolver, e para a educação inclusiva são necessários apoios para que a escolarização ocorra com qualidade. $\mathrm{O}$ profissional de apoio ou cuidador integra a equipe escolar para cuidar da alimentação, higiene e locomoção de estudantes com deficiências múltiplas ou que apresentam um perfil de comprometimento maior. O objetivo desta pesquisa qualitativa descritiva é discutir acerca das possibilidades de atuação do cuidador de estudantes com deficiências, enquanto mediador da Tecnologia Assistiva (TA) no contexto escolar. Aplicou-se um questionário em 46 cuidadores que atuavam em escolas do ensino fundamental, sendo realizada observação participante em duas escolas e entrevistas com os cuidadores. Ao final, foi realizado um grupo focal com 13 participantes. Os dados foram analisados pela análise de conteúdo, da qual emergiram cinco categorias: Mediação da TA em atividades de alimentação, Mediação da TA em situações de locomoção e atenção ao posicionamento dos estudantes para participar das atividades escolares, Mediação da TA em atividades de higiene, Mediação da TA em interações comunicativas e TA potencializadora do desenvolvimento humano: estratégias e aplicações práticas da TA em parceria colaborativa com os professores e outros profissionais.

PALAVRAS-CHAVE: Educação inclusiva. Profissional de apoio. Cuidador. Tecnologia assistiva.

RESUMEN: Todos los alumnos tienen potencial para desarrollarse y para una educación inclusiva se necesita apoyo para que la escolarización se produzca con calidad, incluyendo el profesional de apoyo o cuidador para cuidar la alimentación, higiene y transporte de alumnos con múltiples discapacidades o que tengan un perfil de mayor compromiso. El objetivo de esta investigación descriptiva cualitativa es discutir las posibilidades del cuidador de estudiantes con discapacidad como mediador de la Tecnología de apoyo (TA) en el contexto escolar. Se aplicó un cuestionario a 46 cuidadores que trabajaban en escuelas

${ }^{1}$ Este artigo traz um recorte com dados parciais da Tese de Doutorado da primeira autora.

${ }^{2}$ Universidade Federal da Bahia (UFBA), Salvador - BA - Brasil. Professora Adjunta do Departamento I da Faculdade de Educação (FACED). Doutorado em Psicologia Escolar e do Desenvolvimento Humano (USP). ORCID: https://orcid.org/0000-0002-0724-7378. E-mail: fernanda.queiroz@ufba.br

${ }^{3}$ Universidade de São Paulo (USP), São Paulo - SP - Brasil. Docente da Graduação e da Pós-Graduação do Instituto de Psicologia da USP (IPUSP). Doutorado em Psicologia Clínica (USP). ORCID: https://orcid.org/0000-0002-2061-1832.E-mail: mmelo@usp.br

RIAEE - Revista Ibero-Americana de Estudos em Educação, Araraquara, v. 16, n. esp. 4, p. 3122-3137, dez. 2021. e-ISSN: 1982-5587 DOI: https://doi.org/10.21723/riaee.v16iesp.4.16071 
primarias. La observación participante se realizó en dos escuelas y entrevistas semiestructuradas con los cuidadores. Al final, se realizó un grupo focal, con 13 participantes. Los datos fueron analizados por análisis de contenido y se originaron cinco categorías: Mediación de TA en actividades de alimentación, Mediación de TA en situaciones de locomoción y atención al posicionamiento de los estudiantes para participar en actividades escolares, Mediación de TA en actividades de higiene, Mediación de TA en Interacciones comunicativas y TA que mejoran el desarrollo humano: estrategias y aplicaciones prácticas de TA en asociación colaborativa con profesores y otros profesionales.

PALABRAS CLAVE: Educación inclusiva. Cuidador escolar. Profesional de apoyo. Tecnología de apoyo.

ABSTRACT: All students have the potential to develop and for inclusive education, support is needed for schooling to occur with quality, including the paraprofessional or caregiver to take care of the food, hygiene and transportation of students with multiple disabilities or who have a profile of greater commitment. The objective of this qualitative descriptive research is to discuss the possibilities of the caregiver of students with disabilities as a mediator of Assistive Technology (AT) in the school context. A questionnaire was applied to 46 caregivers who worked in elementary schools. Participant observation was carried out in two schools and semi-structured interviews with caregivers. At the end, a focus group was held, with 13 participants. The data were analyzed by content analysis and gave rise to five categories: Mediation of AT in feeding activities, Mediation of AT in locomotion situations and attention to the positioning of students to participate in school activities, Mediation of AT in hygiene activities, Mediation of AT in communicative interactions and AT that enhance human development: strategies and practical applications of AT in collaborative partnership with teachers and other professionals.

KEYWORDS: Including education. Paraprofessional. Caregiver. Assistive technology.

\section{Introdução}

Pela perspectiva educacional inclusiva todos os estudantes têm potencialidades a desenvolver e buscar formas de contribuir com o seu meio social, dentre eles, encontra-se o Público-Alvo da Educação Especial (PAEE), que apresenta deficiências, seja física, intelectual, sensorial ou múltiplas, com Transtornos Globais do Desenvolvimento (TGD) ou altas habilidades/superdotação, conforme caracterizado pelo Decreto $n^{0}$. 7.611/2011 (BRASIL, 2011).

Historicamente, desde o século XVI, o cuidado junto às pessoas com deficiência foi meramente custodial, e a institucionalização favoreceu a segregação "justificada pela crença de que a pessoa diferente seria mais bem cuidada e protegida se confinada em ambiente separado" (MENDES, 2006, p. 387). Em torno da década de 70, algumas escolas passaram a 
aceitar estudantes com deficiência no ensino comum, porém, a maioria frequentava as classes especiais; este período ficou conhecido por integração, e trazia a ideia de que a pessoa com deficiência deveria se adaptar à escola; por outro lado, a escola não realizava um movimento de reflexão em relação aos seus paradigmas educacionais (BUENO, 1999; MENDES, 2006).

Para que os estudantes com deficiência tenham seu direito à educação preservado, são necessários apoios para que a escolarização inclusiva ocorra com qualidade. Como integrante da equipe escolar, o profissional de apoio ou cuidador tem como atribuições cuidar de ações referentes à alimentação, higiene e locomoção deste estudante, dentre outros aspectos, e assim colaborar para evitar a evasão escolar dos estudantes com deficiências múltiplas ou que apresentam um perfil de comprometimento maior.

Sob o olhar da abordagem histórico-cultural de Vygotski e da CIF - Classificação Internacional de Funcionalidade, Incapacidade e Saúde (OMS, 2015), a Tecnologia Assistiva (TA) colabora sobremaneira para o desenvolvimento dos estudantes com deficiência, possibilitando uma janela voltada à compensação da deficiência ao permitir a execução de tarefas e a participação em atividades de interesse deste estudante, oferecendo oportunidade de participação em seu meio social. Por outro lado, se há estudantes com deficiência que apresentam dificuldades de interação, esta situação pode ser agravada quando há superproteção, falta de estímulos ou preconceito do meio familiar, escolar ou social mais amplo, podendo gerar tendência à passividade, dificuldade de acreditar em si mesmo e no desenvolvimento de suas potencialidades, ocasionando dificuldades de adaptação ao uso da TA e, neste sentido, os profissionais da escola, como os professores e apoios, poderão colaborar implementando ações inclusivas visando reverter esta situação excludente. O Comitê de Ajudas Técnicas (CAT/CORDE/SEDH) define TA como:

[...] uma área do conhecimento, de característica interdisciplinar, que engloba produtos, recursos, metodologias, estratégias, práticas e serviços que objetivam promover a funcionalidade, relacionada à atividade e participação, de pessoas com deficiência, incapacidades ou mobilidade reduzida, visando sua autonomia, independência, qualidade de vida e inclusão social" (BRASIL, 2007).

Caracterizada como uma área interdisciplinar, a TA é apontada em diversas pesquisas na área educacional, que a abordaram e a expuseram em relação à importância dos produtos e recursos para desenvolver um trabalho pedagógico voltado ao PAEE, em diferentes segmentos educacionais (ANDRIOLI, 2017; BERSCH, 2017; GALVÃO FILHO, 2012). Outras se direcionaram a estudar as metodologias, estratégias, práticas e serviços (MANZINI, 2010, 2013; DELGADO GARCIA; PASSONI, 2017; FIORINI, 2018), entre outras. 
A Lei $n^{\circ}$. 13.146/2015, Lei Brasileira de Inclusão da pessoa com deficiência (LBI), menciona que é incumbência do poder público assegurar, criar, desenvolver, implementar, incentivar, acompanhar e avaliar, dentre outros aspectos, a formação e disponibilização de professores para o Atendimento Educacional Especializado (AEE), de tradutores e intérpretes da Libras, de guias intérpretes, bem como a oferta de profissionais de apoio escolar (BRASIL, 2015). De acordo com a LBI, no seu Capítulo I, considera-se profissional de apoio escolar:

[...] pessoa que exerce atividades de alimentação, higiene e locomoção do estudante com deficiência e atua em todas as atividades escolares nas quais se fizer necessária, em todos os níveis e modalidades de ensino, em instituições públicas e privadas, excluídas as técnicas ou os procedimentos identificados com profissões legalmente estabelecidas. (BRASIL, 2015)

Diversos profissionais colaboram com a perspectiva educacional inclusiva, portanto, é importante esclarecer a diferença entre o profissional de apoio e o professor de apoio. De acordo com Lopes e Queiroz (2018), o primeiro, como já mencionado, atua normalmente com a responsabilidade de suporte para alimentação, higiene e locomoção dos estudantes com deficiência, em um papel diferenciado do professor de apoio, que deve possuir uma formação acadêmica especializada em educação especial para dar suporte aos professores do ensino comum nas atividades de planejamento, adaptação e flexibilização curricular.

O profissional de apoio escolar recebe diversas nomenclaturas de acordo com a localidade de sua atuação (cuidador, auxiliar de vida escolar, entre outras), e pela perspectiva dos direitos humanos o cuidado é visto como um direito do cidadão que dele necessite, portanto, neste estudo, o profissional de apoio será denominado cuidador, para enfatizar seu papel de cuidado sob esta égide e não confundir com os demais apoios que o estudante possa vir a precisar em sua trajetória de escolarização.

A mediação do conhecimento se constitui um papel essencial em todo processo educacional e, segundo Vygotski (2003), pode ser realizada pelo adulto, como, por exemplo, o professor, cuidador ou outro parceiro mais experiente, como os colegas de turma. Para Neves (2017, p. 70), de acordo com a abordagem vygotskiana, "o mediador pode estimular a exploração de instrumentos intelectuais, desenvolvendo a crítica e autonomia".

A relevância desta pesquisa para o meio acadêmico e escolar se encaminha no sentido de a atuação do cuidador ser ainda recente no Brasil. Portanto, pouco se conhece sobre seus pensamentos, opiniões, perspectivas, formação e sentimentos, bem como sobre as suas práticas e os reflexos destas na escola e no comportamento dos estudantes e demais profissionais que atuam no ambiente escolar. Configura-se em uma área que necessita ampliar 
os estudos que investiguem a atuação do cuidador enquanto elemento favorecedor da TA na escola.

Assim, apresenta-se como objetivo geral: discutir acerca das possibilidades de atuação do cuidador de estudantes com deficiências enquanto mediador da TA no contexto escolar. Para tanto, foram determinados os seguintes objetivos específicos: conhecer as características e o cotidiano profissional do cuidador, bem como reconhecer as contribuições reveladas pelos cuidadores enquanto mediadores da TA em escolas municipais de ensino fundamental.

\section{Percurso metodológico}

Trata-se de uma pesquisa qualitativa descritiva, para a qual foi traçado o seguinte percurso metodológico: em um primeiro momento, em busca de conhecer as características e o cotidiano profissional desses apoios, foi aplicado um questionário em 46 cuidadores que atuavam em escolas do ensino fundamental de uma cidade localizada no estado de São Paulo. A seguir, foi realizada a observação participante com registro em diário de campo em duas escolas desta rede, escolhidas aleatoriamente, dentre as que possuíam mais de um estudante com deficiência e que contassem com a atuação do cuidador, com a finalidade de reconhecer as possibilidades de atuação desse profissional frente à TA no ambiente escolar. Ao final de 40 horas de observação, distribuídas em dez dias letivos, foi realizada uma entrevista semiestruturada com esses profissionais. Para finalizar, os profissionais foram convidados a participar de uma sessão de grupo focal, visando discutir acerca das possibilidades de sua atuação junto aos estudantes com deficiências, enquanto mediador da TA no contexto escolar, expondo sobre seus saberes e fazeres, possibilidades e dificuldades encontradas na escola, bem como outros profissionais e recursos que subsidiam seu trabalho ou geram entraves, dente outros assuntos pertinentes. No grupo focal compareceram 13 cuidadores.

Para isso, houve necessidade de autorização da rede de ensino, do comitê de ética em pesquisa e assinatura do Termo de Consentimento Livre e Esclarecido (TCLE) dos participantes. Os dados foram analisados conforme a análise de conteúdo proposta por Bardin (2011), o que resultou em cinco categorias temáticas de mediação da TA no ambiente escolar realizada pelos cuidadores. 


\section{Resultados e discussão}

Dentre os 46 participantes deste estudo todos realizavam uma jornada de trabalho de 40 horas semanais, somente dois eram do sexo masculino, 18\% possuíam nível de escolarização superior e $82 \%$ ensino médio. Trabalhavam em média há três anos na função e atendiam entre quatro e cinco estudantes por período que apresentavam paralisia cerebral, autismo, deficiências múltiplas, entre outras deficiências.

As principais funções realizadas envolviam a alimentação, a higiene e a locomoção destes estudantes. $\mathrm{Na}$ rede de ensino pesquisada há estagiários da área de pedagogia para auxiliar o professor no acompanhamento das atividades pedagógicas desenvolvidas em sala de aula na maioria das turmas que têm estudantes com deficiência.

Os participantes demonstraram qual sua concepção sobre TA, bem como as observações e contribuições que eles fazem diante da implementação no ambiente escolar para os estudantes com deficiência. A seguir, serão relatadas e discutidas as categorias que emergiram da análise dos dados.

\section{Mediação da Tecnologia Assistiva em atividades de alimentação}

Esta categoria se refere a atividades de alimentação observadas ou relatadas pelos cuidadores que envolviam sua atuação estimulando o uso da TA pelo estudante com deficiência no momento das refeições no ambiente escolar, como hora do lanche e almoço. Neste contexto, foi observado o uso de auxílios para a vida diária e vida prática (BERSCH, 2017) pelos estudantes com deficiência para situações envolvendo a alimentação no ambiente escolar, como, por exemplo, o uso de copo com bico e alça para evitar derramamento do líquido; uma profissional se queixou da falta da colher entortada, recurso que facilitaria a alimentação da estudante. Para alguns estudantes era realizado o auxílio para levar a colher à boca, outros se alimentavam com autonomia e a cuidadora ficava próxima, atenta, verificando quanto a possíveis engasgamentos.

Os participantes também relataram situações nas quais confeccionavam recursos para a vida prática e diária e como é positivo quando podem contar com o apoio de especialista, como, no caso observado, o olhar de um terapeuta ocupacional, confirmando ou não a necessidade do uso do recurso diante do perfil funcional do estudante atendido, como menciona C5: “porque as vezes você está com um problema lá de entortar a colher, mas, 
talvez não precise entortar a colher, talvez com uma colher normal a criança já consiga comer"4.

Uma estratégia observada foi: a profissional deixava a sobremesa no campo de visão do estudante enquanto o alimentava, para que ele soubesse que a receberia após o almoço, porém, tomando o cuidado de deixá-la a uma distância que ele não a derrubasse devido a apresentar muitas ocorrências de espasticidade de seus membros superiores. Situações como esta demonstram que este profissional deve ter em sua formação, seja inicial ou continuada, conhecimentos sobre TA e sua relação com o perfil funcional do estudante, para saber determinar qual o recurso ou estratégia é necessário ser aplicado nas ocorrências do seu cotidiano profissional.

Houve também outros relatos em relação à alimentação, como C9 mencionou: "No meu caso, o aluno ia para escola e só tomava na mamadeira, tudo era batido e dado na mamadeira, aí as meninas (referindo-se às supervisoras e especialistas da secretaria da educação) falaram, porque a gente não troca para o copo que tem bico de silicone. A gente trocou pelo copo e ele aceitou, agora, vamos trocar para a colher, a colher, ele recusou por causa do metal, então, vamos colocar uma de plástico, porque a de silicone nunca foi para a escola, então, vamos na de plástico mesmo, e ele aceitou numa boa e eu acho que isso ajuda muito a gente, por isso que eu acho que sim (referindo-se à atuação do cuidador enquanto mediador da TA voltada aos estudantes com deficiência na escola)".

Em continuidade $\mathrm{C} 5$ expressou:

Tem um aluno lá na escola que, ele na escola, toma o suco, o iogurte, tudo no copo, mas na casa dele, a mãe dá na mamadeira ou na colher, aí eu abordei isso um dia que o pai perguntou se ele estava comendo direitinho, eu falei, sim, ele até está tomando o iogurte ou o suco no copo. No copo? Eu falei, é, na sua casa sua esposa não dá? Ele falou, não, ela só dá na mamadeira. Eu falei, aqui ele toma no copo, eu dou no copo, seguro para ele, porque ele é tetra (referindo-se a tetraplegia), eu seguro e ele 'manda pra dentro'. Aí ele ficou assim! (expressão de espanto). Não sei se eles estão fazendo em casa porque eu não fico muito conversando com os pais. Mas, assim, se na escola ele toma, em casa a mãe poderia fazer a mesma coisa, para ele vai ser ótimo.

Em relação às dificuldades alimentares dos estudantes relatadas pelos participantes, C4 expõe:

É um tema importante! Tenho uma aluna com PC que tinha um acompanhamento com fonoaudióloga, que mostrava um excelente avanço na deglutição. Porém, ela perdeu o acompanhamento. O que eu procuro fazer,

${ }^{4}$ Neste estudo as falas dos participantes encontram-se entre aspas e em itálico.

RIAEE - Revista Ibero-Americana de Estudos em Educação, Araraquara, v. 16, n. esp. 4, p. 3122-3137, dez. 2021. e-ISSN: 1982-5587 
é sempre lembrá-la em mastigar os alimentos devagar. Pois ela tem o costume de engolir e não mastigar. Faço movimentos repetitivos com a mão, indicando a mastigação que ela tem que fazer. É um trabalho longo que eu estou tendo com a minha aluna. No qual eu procuro sempre a incentivar, $e$ fazer com que ela tenha uma certa evolução.

Diante do relato, $\mathrm{C} 11$ complementa:

No periodo em que trabalhei em outra escola, houve um caso de suspeita de disfagia de aluno com PC ele foi encaminhado pela fonoaudióloga para realização do exame videofluoroscopia, deixando a orientação que, na comprovação do transtorno a apresentação dos alimentos e líquidos a ele oferecidos deveriam sofrer alguns processos diferenciados, porém, logo após a mesma informou que o resultado era negativo.

C10 comentou: "Devemos procurar a orientação do profissional para melhor alimentálo conforme as suas necessidades", e C12:

Na Unidade em que trabalho, há dois alunos com disfagia. Ambos com características bem parecidas na forma de engolir o alimento, costumam inclinar a cabeça para trás para facilitar. Procuro ficar bem atenta durante a refeição deles, pois fico preocupada com um possivel engasgamento. Tento ajudá-los da melhor forma, misturando e amassando os alimentos.

Nota-se pelos relatos expostos que, para além do recurso, estes profissionais utilizamse, majoritariamente, de estratégias e práticas de TA no seu cotidiano junto ao estudante com deficiência e expressam o quanto a parceria colaborativa com outros profissionais que ofertam serviços de TA como, por exemplo, o terapeuta ocupacional e o fonoaudiólogo, trazem segurança para o seu exercício profissional e que, na ausência deles, procuram realizar o melhor trabalho possível com o conhecimento que possuem, o que denota necessidade formativa desses profissionais de acordo com o seu campo de atuação.

\section{Mediação da Tecnologia Assistiva em situações de locomoção e atenção ao posicionamento dos estudantes para participar das atividades escolares}

Esta categoria se refere a atividades de locomoção observadas ou relatadas pelos cuidadores em situações de locomoção ou posicionamento do estudante com deficiência no ambiente escolar. Sobre os auxílios de mobilidade, que se refere a "bengalas, muletas, andadores, carrinhos, cadeiras de rodas manuais ou elétricas, scooters e qualquer outro veículo, equipamento ou estratégia utilizada na melhoria da mobilidade pessoal" (BERSCH, 2017, p. 9). C9 comentou: “A gente não tem muito acesso aos recursos, é basicamente, mais a cadeira de rodas mesmo". 
Em relação à adequação postural (BERSCH, 2017), os participantes relataram adaptação em alguns mobiliários escolares. C10 mencionou: "Um suporte que houve lá na escola, fizeram para encaixar uma cadeira de rodas que não cabia, para o aluno poder usar a carteira escolar, ficou assim, suspensa e a cadeira de rodas deles cabe certinho embaixo". C11: "Na minha escola, foi soldada algumas alcinhas na cadeira do aluno para que a criança não caísse para os lados".

De acordo com o estudo de Piovezanni, Rocha e Braccialli (2014), o mobiliário escolar adequado para o estudante com paralisia cerebral é muito importante, podendo maximizar as habilidades funcionais, favorecer a estabilidade postural e interferir na coordenação motora fina, refletindo na melhora de desempenho das atividades escolares.

\section{Mediação da Tecnologia Assistiva em atividades de higiene}

Esta categoria se refere a atividades de apoio à higiene observadas ou relatadas pelos profissionais em situações cotidianas do estudante com deficiência no ambiente escolar. Neste sentido, os cuidadores orientam os estudantes que têm condições para tal sobre o uso das barras de apoio nos sanitários, higienização das mãos, entre outros. Diante disso, cabe mencionar que as duas escolas observadas contavam com a acessibilidade arquitetônica adequada nos banheiros, quanto ao tamanho das portas, altura do sanitário, lavatórios e barras de apoio, porém, infelizmente, esta ainda não é uma realidade em muitas escolas públicas nacionalmente, configurando-se em uma barreira enfrentada pelos estudantes com deficiência em muitas escolas.

Um aspecto relevante se refere às técnicas de transferência da cadeira de rodas para o trocador e vice-versa para os estudantes que usam fraldas. Os participantes mencionaram conhecer recursos de TA que auxiliam nas situações de transferências, como, por exemplo, o elevador individual para transferência elétrico, porém comentaram ser muito caro e, por isso, muito pouco provável poderem contar com esses recursos no ambiente escolar. Outro recurso, mais barato, que poderia auxiliar na transferência do estudante da cadeira para o vaso sanitário, é o disco de transferência, que é usado sendo colocado no piso, porém, ele também não foi observado em nenhuma das escolas.

Relataram contar com o apoio de outro funcionário da escola nas situações de transferência de estudante adolescente ou adulto da cadeira para o trocador, devido ao peso requerido, porém, foi percebido que este contexto gera muitas situações controversas, pois outras participantes mencionaram que raramente alguém se habilita a ajudar, porque acham 
que os estudantes com deficiência são apenas tarefa do cuidador, assim, sentem que precisam sempre ficar pedindo favores, fato que causa conflitos nas relações interpessoais no ambiente escolar.

A educação inclusiva não pode ser responsabilidade de um único profissional na escola, seja ele o professor do AEE ou o cuidador: a inclusão se dá no cotidiano escolar com cada um fazendo a sua parte e assumindo as responsabilidades inerentes a sua função de maneira colaborativa; para a inclusão acontecer, não basta inserir o estudante com deficiência em uma turma na escola, são necessários apoios planejados de acordo com a característica funcional de cada um, dentre outros recursos.

Nos momentos de apoio à higiene é muito importante o profissional verificar o corpo do estudante, se não há marcas ou escaras devido ao posicionamento, como foi observada em uma situação em que o estudante estava sem os apoios adutores da cadeira de rodas, e por não haver sensibilidade de membros inferiores, devido à mielomeningocele ${ }^{5}$, ele não percebeu que o assento da cadeira estava pressionando sua coxa, causando uma marca avermelhada que, se não fosse percebida a tempo, poderia tornar-se uma lesão no local. A profissional providenciou um almofadado provisório para o local e avisou a direção da escola, que comunicou a família do ocorrido e alertou que deveria enviar o estudante para a escola com o acessório adutor na sua cadeira.

\section{Mediação da Tecnologia Assistiva em interações comunicativas}

Esta categoria se refere a atividades de interações comunicativas, tanto do cuidador com o estudante como entre estudantes, intermediadas por alguma ação do profissional, que foram observadas ou relatadas pelos participantes. Sobre comunicação, C11 comentou: "Quando estava em outra escola o professor da sala de recursos fazia uso de alguns sistemas de comunicação, na escola que estou agora não é utilizado" e C5: "Aqui na escola veio a prancha para um aluno, mas ele não respondeu a nenhum sistema de comunicação que a professora ofereceu”.

Por outro lado, outros participantes relataram acerca do uso da Comunicação Suplementar e Alternativa (CSA); C7 falou: "na minha escola tinha um aluno adolescente que usava CSA"; C10: "Sim, acompanhei (estudante usuário de CSA) no caso e um ótimo aprendizado e desenvolvimento para o aluno"; C7: "Sim, já acompanhei crianças que

\footnotetext{
${ }^{5}$ Mielomeningocele, também conhecida como espinha bífida, é uma anomalia congênita da coluna vertebral, que
} se projeta da medula externamente por uma cavidade. 
utilizam e achei muito boa essa técnica" e C2: "As imagens da sequência de escovação para algumas crianças são necessárias".

Ainda sobre CSA, C3 acredita ser: "Muito aproveitável, para quem tem alunos com TEA" e C12: “[...] o fato de usar imagens para indicar o passo a passo, faz com que o aluno assimile com mais facilidade". A mesma participante verbalizou sobre estudantes com autismo: "Percebo as dificuldades deles principalmente com barulho. Por exemplo, tem um aluno que no intervalo ele fica mais agitado, não interage com os outros alunos. Além disso, ele tem um fato especifico, todo intervalo ele gosta de ficar no banheiro, mexendo na torneira". Este comentário nos suscita a reflexão acerca das estratégias que as crianças com TEA utilizam para se acalmarem diante de estímulos sensoriais (como o barulho do recreio, por exemplo) e como os cuidadores podem colaborar neste processo. Neste sentido, Posar e Visconti (2018) afirmaram que as alterações sensoriais são uma característica muito frequente no quadro clínico de crianças com TEA e esta reatividade sensorial atípica pode explicar muitos de seus comportamentos. Este aspecto deve ser levado em consideração no manejo diários dessas crianças em todos os contextos nos quais elas vivem.

Sobre a confecção das pranchas de comunicação, C11 comentou: “A confecção do PECS, dentro da escola é fácil. Não precisa nem de impressora colorida, pinta mesmo. É muito fácil e para um autista no caso é primordial e deve começar na Educação Infantil, que já segue no fundamental’. A mesma participante exemplifica:

o PECS, aqueles das imagens, então, o aluno poderia ter com ele para o cuidador usar, a professora usar. Então assim, se o cuidador usar fora da sala de aula e der muito certo, dentro da sala de aula ele não vai poder interferir, se vai ser usado ou não, entendeu? Pode sim, ser usados aqui e lá, no pedagógico e fora, lá fora pode dar muito certo, se o aluno trouxer, se for confeccionado pelo professor da sala de recursos, não sei por quem, até pela família. Mas dentro da sala de aula, o cuidador já não pode garantir isso. O que diz respeito a nós quando já se tem uma estrutura ou recurso bom. Eu acho que dá muito certo.

Em relação ao uso da CSA em diversos ambientes da escola, C9 afirmou:

Eu tenho um PECS dentro do banheiro, indicando o que pode e o que não pode, o que vai ser feito dentro do banheiro, só que dentro da sala de aula, ele já não tem isso, então dentro da sala de aula ele fica solto, apesar, a gente tem alguns acessos, e a gente consegue utilizar, mas dentro da sala é um pouco mais difícil, então quando a gente tem a gente utiliza sim, e é muito bom.

Referente à fala da colega, C11 se posicionou: "E neste caso quem perde é o aluno. Porque ele tem lá, mas não tem aqui”. 
Neste contexto, foi perguntado se eles perceberam alguma diferença no comportamento da criança ao usar o recurso de CSA. C9:

Muito, dentro do banheiro ele sabe que no lixo ele não pode mexer, a torneira ele abre, lava a mão e sabe que não é para bagunçar, dentro do banheiro não tem esta bagunça toda de subir nos lugares, agora, dentro da sala de aula como não tem este limite, ele sobe na cadeira, ele joga as coisas, ele bagunça o lixo, então, assim, eu acho que se todo mundo conseguisse falar a mesma língua, ele conseguiria entender bem mais.

A exposição da cuidadora valoriza a importância do uso da CSA para estudantes com este perfil; a CSA "é uma área da ciência que se dedica a desenvolver recursos, estratégias, processos e técnicas voltados à comunicação de indivíduos com restrições na comunicação verbal" (DONATI: DELIBERATO, 2017, p. 53).

As pesquisadoras Bittencourt e Fumes (2017) procuraram fomentar a reflexão acerca da importância de disponibilizar um sistema de comunicação alternativa no intuito de aumentar o potencial de comunicação das participantes da pesquisa; tal fato permitiu conhecer suas percepções quanto aos professores, escola e amigos, seus interesses e dificuldades, experiências positivas, negativas e sentimentos.

Tecnologia Assistiva potencializadora do desenvolvimento humano, estratégias e aplicações práticas da TA em parceria colaborativa com os professores e outros profissionais

Esta categoria se refere às estratégias e aplicações práticas da TA observadas ou relatadas pelos cuidadores em situações de acompanhamento ao estudante com deficiência no ambiente escolar. A TA permite ao estudante com deficiência demonstrar suas potencialidades e, neste sentido, os participantes verbalizaram como essencial a parceria colaborativa com os professores e outros profissionais que atuam junto ao estudante.

Um participante relatou: C12: "Tem a professora da Sala de recursos que me ajuda muito, [...] na medida do possível porque são muitos alunos na escola, então, sempre que possível eu peço ajuda”. C8 prosseguiu: "Porque ela (a professora) é interessada em interagir com criança”. E C4 complementou: "É a vontade, né? Se cada um tivesse vontade, para todos da equipe trabalharem, melhorassem para o aluno, seria, uma contribuição enorme, mas, é isso, é o querer, é a vontade, é pensar no aluno, no que é melhor para o aluno, basta o querer".

Os cuidadores comentaram sobre a importância da parceria colaborativa com o professor do AEE e com os profissionais que acompanham o estudante como, por exemplo, 
fonoaudiólogo, fisioterapeuta, psicólogo, entre outros, para colaborarem no sentido de subsidiarem os cuidadores fornecendo mais estratégias para aplicações práticas. Acrescenta-se aqui a necessidade de o professor do ensino comum também fazer parte desta rede colaborativa inclusiva e, assim, trazemos algumas falas de participantes.

C2 falou:

O cuidador pode também ser o mediador dessa comunicação, porque eu trabalhei numa escola, que a menininha chorava muito e um dos recursos que eu consegui foi por uma música para ela escutar para se acalmar e ai a professora viu, levou um notebook para a sala de aula e começou a usar a música também para atividades pedagógicas. Tem o querer do profissional também. Eu não falei, a professora só viu e já usou o recurso, não tem esta abertura com todos.

Este relato se refere a uma estratégia adotada pelo cuidador para a adaptação escolar da aluna e que foi aproveitada pela professora para a prática pedagógica, fato que esclarece muito acerca do potencial que há quando ocorre um trabalho inclusivo em conjunto com todos os profissionais da escola atuando em prol do aluno. Neste sentido, não há um saber hierarquizado, e sim deve-se aproveitar todos os olhares para se conhecer bem o estudante e assim traçar as melhores práticas educativas.

Porém, nota-se que a participante se ressente, ao expressar que "não tem esta abertura com todos", ou seja, não são todos professores que estão atentos a esta percepção, este olhar inclusivo de acolher o estudante com deficiência e adaptar as práticas pedagógicas ou mesmo dialogar com o cuidador acerca das potencialidades e dificuldades observadas no estudante.

\section{Considerações finais}

Percebe-se pelos relatos apresentados nas categorias que os cuidadores necessitam e utilizam o conhecimento sobre TA no seu cotidiano profissional, porém revelaram uma concepção de TA somente como recursos, embora tenham relatado diversas estratégias que utilizam em sua prática profissional. Também expressaram a necessidade de um aprimoramento do trabalho educativo colaborativo dentro e fora da sala de aula, no ambiente escolar, e expuseram como sugestão usar os recursos de forma integrada, que expressaram como: "falar a mesma língua".

Importante deixar claro que os cuidadores não são os únicos mediadores da TA no ambiente escolar, porém, sua contribuição é relevante, principalmente em atividades fora da sala de aula, como hora do recreio, alimentação, interações na hora da entrada e saída, 
atividades na quadra ou externas, como excursões, entre outras. Assim, os apoios ofertados na educação inclusiva devem ser implementados de acordo com os características e necessidades dos estudantes e avaliados periodicamente quanto à viabilidade de sua permanência. Um apoio não deve ser instituído somente pelo fato de o estudante apresentar uma deficiência, ou seja, estudantes com o mesmo diagnóstico podem precisar de apoios diferenciados, porque são pessoas diferentes tanto em suas características biológicas quanto na história de vida e desenvolvimento.

Diante deste contexto, conclui-se que o cuidador poderia encontrar seu sentimento de pertença dentre os profissionais que prestam serviços de TA, devido ao caráter interdisciplinar de sua atuação, relatado pela parceria com supervisores, especialistas e professor do AEE, e a expressa necessidade de parceria com os professores do ensino comum, condizente com a definição de TA, que se constitui uma área de caráter interdisciplinar promotora da funcionalidade visando a participação desses estudantes, incentivando sua autonomia, inclusão escolar e qualidade de vida neste ambiente com a maior independência possível. Para isso, faz-se necessário investimentos na formação e no aperfeiçoamento profissional dos cuidadores para que possam contribuir para a efetivação de uma educação mais inclusiva.

Aponta-se como positivo um estreitamento de ações estruturadas, supervisionadas pelo professor do AEE, que se revelaram ainda muito distantes e de iniciativa pessoal, dependendo do perfil de ambos. Não há um planejamento sistematizado desta parceria colaborativa, seja entre o professor do AEE ou do ensino comum. Há várias boas ações ocorrendo de forma isolada que poderiam ser potencializadas em benefício do estudante se fossem mais bem articuladas no ambiente escolar.

\section{REFERÊNCIAS}

ANDRIOLI, M. G. P. Desenvolvimento de recursos na área de Tecnologia Assistiva: desafios e possibilidades em Institutos Federais. 2017. Tese (Doutorado em Educação) Universidade de São Paulo, São Paulo, 2017.

BARDIN, L. Análise de conteúdo Trad: L. de A. Rego \& A. Pinheiro. Lisboa: Edições 70, 2011.

BERSCH, R. Introdução à tecnologia assistiva. Porto Alegre, 2017. Disponível em: http://www.assistiva.com.br/Introducao_Tecnologia_Assistiva.pdf. Acesso em: 30 abr. 2021.

BITTENCOURT, I. G. S.; FUMES, N. L. F. A tecnologia assistiva Scala como recurso para produção de narrativas e registro de dados nas pesquisas em educação: uma experiência com pessoas adultas com transtorno do espectro autista. Revista Ibero-Americana de Estudos 
em Educação, Araraquara, v. 12, n. esp. 2, p. 1481-1495, ago. 2017. DOI: http://dx.doi.org/10.21723/riaee.v12.n.esp.2.1304

BRASIL. Secretaria dos Direitos Humanos. Comitê de Ajudas Técnicas. Ata da III reunião do Comitê de Ajudas Técnicas - CAT/CORDE. Brasília, DF, 2007. Disponível em:

https://www.assistiva.com.br/Ata_VII_Reuni\%C3\%A3o_do_Comite_de_Ajudas_T\%C3\%A9 cnicas.pdf. Acesso em: 30 abr.2021.

BRASIL. Decreto n. 7.611, de 17 de novembro de 2011. Promulgado pela Presidência da República, dispõe sobre a educação especial, o atendimento educacional especializado e dá outras providências. Brasília, DF, 2011. Disponível em:

http://www.planalto.gov.br/ccivil_03/_ato2011-2014/2011/decreto/d7611.htm. Acesso em: 19 nov. 2019.

BRASIL. Lei n. 13.146, de 6 de julho de 2015. Institui a Lei Brasileira de Inclusão da Pessoa com Deficiência (Estatuto da Pessoa com Deficiência). Brasília, DF, 2015. Disponível em: http://www.planalto.gov.br/ccivil_03/_ato2015-2018/2015/lei/113146.htm. Acesso em: 19 nov. 2019.

BUENO, J. G. S. Crianças com Necessidades Educativas Especiais, política Educacional e a Formação de Professores: generalistas ou especialistas? Revista Brasileira de Educação Especial, n. 5, p. 7-25, 1999. Disponível em:

https://abpee.net/homepageabpee04_06/sumarios/sumariorevista5.htm. Acesso em: 26 abr. 2021.

DELGADO GARCIA, J. C.; PASSONI, I. R. A relação do Emprego Apoiado com a qualidade de vida das pessoas com deficiência: efeitos baseados em evidências. In: PASSONI, I.; DELGADO GARCIA, J. C. (org.). Emprego Apoiado e Qualidade de Vida: Como se faz. 1. ed. São Paulo: Mundial Gráfica, 2017. v. 1, p. 12-31.

DONATI. G. C. F; DELIBERATO, D.; Questionário de Necessidades de Informação em Linguagem e Comunicação Alternativa (QNILCA-F). Revista Brasileira de Educação Especial, Marília, v. 23, n. 1, p. 53-66, jan./mar. 2017.

FIORINI, M. L. S.; MANZINI, E. J. Estratégias de professores de educação física para promover a participação de alunos com deficiência auditiva nas aulas. Revista Brasileira de Educação Especial, Marília, v. 24, n. 2, p. 183-198, abr./jun. 2018.

GALVÃO FILHO, T. A. Tecnologia assistiva: favorecendo o desenvolvimento e a aprendizagem em contextos educacionais inclusivos. In: GIROTO, C. R. M.; POKER, R. B.; OMOTE, S. (org.) As tecnologias nas práticas pedagógicas inclusivas. Marília, SP: Oficina Universitária; São Paulo: Cultura Acadêmica, 2012. p. 65-92.

LOPES, M. M.; QUEIROZ, F. M. M. G. Profissionais de apoio à inclusão escolar : aspectos legais. In: JORNADA DE EDUCAÇÃO ESPECIAL, 14.; CONGRESSO INTERNACIONAL DE EDUCAÇÃ̃O ESPECIAL E INCLUSIVA, 2., 2018, Marília. Anais [...]. Marília, SP: Universidade Estadual Paulista, Faculdade de Filosofia e Ciências, 2018. p. 846-854. Disponível em: http://ftp.ocs-jee.marilia.unesp.br/anais-jornada2018.pdf. Acesso em: 26 abr. 2021. 
MANZINI, E. J. Possíveis variáveis para estudar as salas de recursos multifuncionais. In: JESUS, D. M.; BAPTISTA, C. R.; CAIADO, K. R. M (Org.) Prática pedagógica na educação especial: multiplicidade no atendimento educacional especializado. Araraquara, SP: Junqueira \& Marin, 2013.

MANZINI, E. J. Recurso pedagógico adaptado e estratégias para o ensino de alunos com deficiência física. In: MANZINI, E. J.; FUJISAWA, D. S. (Org.) Jogos e recursos para comunicação e ensino na educação especial. Marilia, SP: ABPEE, 2010. p. 117-138.

MENDES, E. G. A radicalização do debate sobre inclusão escolar no Brasil. Revista Brasileira de Educação, v. 11, n. 33, p. 387-559, set./dez. 2006.

NEVES, B. C. Tecnologia e mediação: uma abordagem cognitiva da inclusão digital. Curitiba, PR: Ed. CRV, 2017.

ORGANIZAÇÃO MUNDIAL DE SAÚDE. CIF: Classificação internacional de funcionalidade, incapacidade e saúde. EDUSP, 2015.

POSAR, A.; VISCONTI, P. Sensory abnormalities in children with autism spectrum disorder. Jornal de Pediatria, Sociedade Brasileira de Pediatria, Rio de Janeiro, v. 4, n. 94, p. 342$350,2018$.

VYGOTSKI, L. S. A formação social da mente: o desenvolvimento dos processos Psicológicos Superiores. São Paulo: Martins Fontes, 2003.

\section{Como referenciar este artigo}

QUEIROZ, F. M. M. G.; MELO, M. H. S. Profissional de apoio como mediador da tecnologia assistiva no ambiente escolar. Revista Ibero-Americana de Estudos em Educação, Araraquara, v. 16, n. esp. 4, p. 3122-3137, dez. 2021. e-ISSN: 1982-5587. DOI: https://doi.org/10.21723/riaee.v16iesp.4.16071

Submetido em: 05/09/2021

Revisões requeridas em: 30/10/2021

Aprovado em: 10/12/2021

Publicado em: 30/12/2021 